\title{
Population dynamics, spatial dispersion and somatic growth of the sand fiddler crab Uca pugilator
}

\author{
David R. Colby and Mark S. Fonseca \\ National Marine Fisheries Service, NOAA, Southeast Fisheries Center, Beaufort Laboratory, Beaufort, \\ North Carolina 28516, USA
}

\begin{abstract}
While fiddler crabs, Uca spp., are important constituents of the diets of fishes, birds and mammals, little is known of their population dynamics or somatic growth under natural conditions. A stratified random design was used to sample a population of Uca pugilator on a 3.9 ha study area on Shackleford Banks, North Carolina, USA. Samples were taken at approximately monthly intervals between March 1979 and September 1980 to obtain estimates of numbers, biomass and size composition. Carapace widths, sex and reproductive stage were measured, and population biomass estimates were calculated from separate dry-weight/carapace-width regressions for males, ovigerous and nonovigerous females. Somatic growth was estimated from analysis of size-class modes through time. Numbers of fiddler crabs ( $\geq 5 \mathrm{~mm}$ ) in the study area fluctuated between 1,348,000 and 2,544,000 over the 18 mo period. Trends in numbers over time were generally parallel for the 2 sexes, but females were consistently more abundant than males. The preponderance of females was most pronounced in size classes from 10 to $15 \mathrm{~mm}$. Average dry-weight biomass was $4.30 \mathrm{~g} \mathrm{~m}^{-2}$ for males and $6.12 \mathrm{~g} \mathrm{~m}^{-2}$ for females. Indices of dispersion revealed that crabs become progressively less aggregated during spring and summer, and progressively more so during fall and winter. Ovigerous females were observed from May through August. Only $1 \%$ of ovigerous females were $<10 \mathrm{~mm}$ (mean size $=13.6$ $\mathrm{mm}$ ). Somatic growth varied with season, sex and stage of reproductive maturity. Molting crabs were encountered between May and November. Crabs that were $6 \mathrm{~mm}$ in carapace width in April had grown to about $13 \mathrm{~mm}$ by the following September, but during the reproductive season, growth of females appears to diminish or cease temporarily when they attain sexual maturity.
\end{abstract}

\section{INTRODUCTION}

Fiddler crabs, Uca spp., constitute a significant component of the intertidal macrofaunal biomass in temperate and tropical estuaries. Through their by-products and their burrowing and feeding activities, they influence the transfer of nutrients and energy from intertidal areas to the estuary in general (Montague, 1980), and they are important constituents of the diets of numerous fishes, birds and mammals (Crane, 1975).

Sheltered intertidal sandflats between Cape Cod, Mass., and southern Florida (USA) often harbor large numbers of the sand fiddler crab Uca pugilator. Although $U$. pugilator has been utilized extensively for physiological and behavioral research (e.g. Crane, 1975), little quantitative information is available on its population ecology, and to our knowledge nothing has been published concerning its population dynamics. Such information, however, is fundamental to a com- prehensive understanding of this organism's role in natural processes, especially in defining the coupling between intertidal areas and fisheries. Two other species, $U$. pugnax and $U$. minax, are also found along the east coast of the United States, but because of their different substrate and salinity requirements, they are not usually found in close association with $U$. pugilator (Teal, 1958).

The primary objectives of our investigation were to: (1) measure changes in numerical abundance and biomass through time; (2) determine the patterns of dispersion for the 2 sexes; (3) delineate the season of reproduction; and (4) determine the annual pattern of somatic growth. Secondary objectives included: (1) examining demographic parameters in relation to location along an environmental gradient; and (2) determining the size at which females first reproduce. 


\section{MATERIALS AND METHODS}

The study site was a portion of a 40 ha intertidal sandflat on the western end of Shackleford Banks, a barrier island south of Beaufort, N. C., USA, (Fig. 1). The flat is nearly level (slope $<0^{\circ} 3^{\prime}$ ) and resident fiddler crabs tend to remain close to their burrows, rather than moving downslope to form feeding aggregations at the water's edge, as they do on intertidal beaches having slopes $>2^{\circ}$ (Fig. 2) (Allen and Curran,

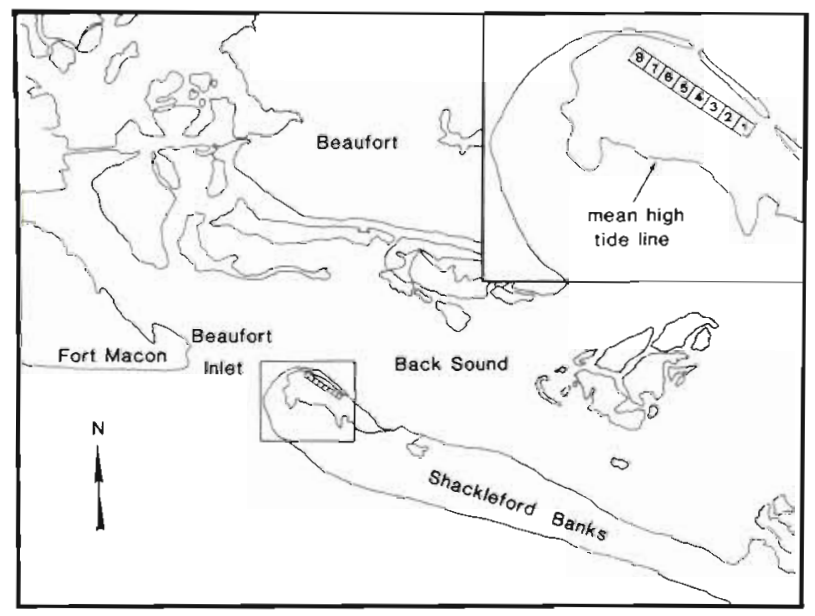

Fig. 1. Study area on North Carolina coast. Inset: 8 strata comprising the study area; overall dimensions: $70 \times 559 \mathrm{~m}$

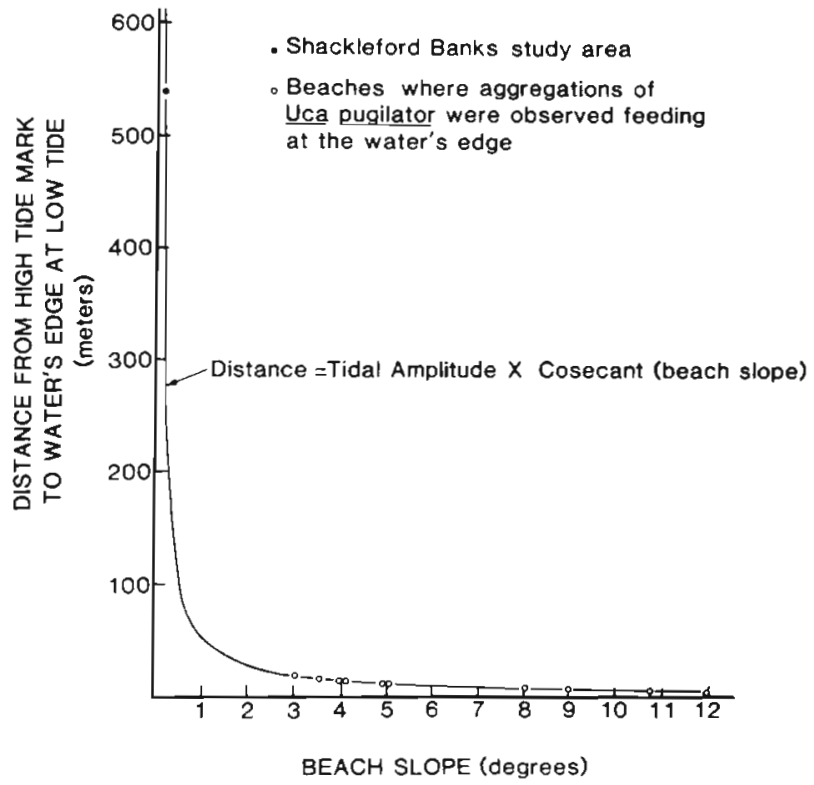

Fig. 2. Relation between horizontal distance from high tide mark to water's edge at low tide and slope of an intertidal beach in the vicinity of Beaufort, N.C. (USA), where tidal amplitude averages $0.94 \mathrm{~m}$. Open circles: 10 intertidal beaches near Beaufort where beach slope measurements were made and where feeding aggregations at the water's edge were observed in August 1982
1974). This behavioral characteristic and the crabs tendency to enter their burrows at the approach of an observer reduced alien dispersion effects and simplified sampling of the population to estimate population parameters. Tidal amplitude at Beaufort averages about $0.94 \mathrm{~m}$ over the lunar cycle. Therefore the horizontal distance from the high tide line to the water's edge at low tide exceeds $50 \mathrm{~m}$ on beaches having a slope of $<1^{\circ}$ (Fig. 2). On rising tide, water tends to move across the surface at approximately $1 \mathrm{~m} \mathrm{~min}^{-1}$. Over the lunar cycle the high tide line shifts a considerable distance horizontally on the flat, producing a substantial gradient in frequency and duration of tidal inundation.

A berm rising about $0.5 \mathrm{~m}$ above the sandflat forms the northern and western borders and separates the flat from Back Sound (Fig. 1). The sandflat and the dunes to the south have been formed by natural processes and did not exist before 1953. The sandflat slopes downward from west to east. Water drains not only off the east end but also through two channels that transect the berm on the northern edge. Two blue-green algae, Microcoleus chthonoplastes and Lyngbya aestuarii, form mats on less well-drained portions of the sandflat (Hans Paerl, pers. comm.). Macrophytic vegetation on the flat is limited to scattered, sparse stands of salt marsh cordgrass Spartina alterniflora. Feral horses, cattle and sheep regularly graze the cordgrass, which seldom extends more than about $15 \mathrm{~cm}$ above the sediment.

A rectangular area measuring 70 by $559 \mathrm{~m}$ on the north side of the sandflat was selected as the study site (Fig. 1). The long axis is parallel with the gradient, the elevation increasing about $30 \mathrm{~cm}$ from east to west. The area was subdivided into 8 equal squares (strata) to assure that samples were taken over the entire gradient and to permit us to relate differences in the population to location on the gradient. A permanent stake was placed at the northeast corner of each stratum. Strata were numbered sequentially from east to west.

We took a sediment core to a depth of $25 \mathrm{~cm}$ from the center of each of the eight strata to determine how sediments varied over the study area. Each core was divided into 6 segments ( 0 to 1,1 to 5,5 to 10,10 to 15 , 15 to 20 , and 20 to $25 \mathrm{~cm}$ ). Each segment was analyzed for percent silt-clay (wet sieving) A.S.T.M. (1963), sand fraction distribution (dry sieving) (Folk and Ward, 1957) and percent organic matter (by gravimetric measure after combustion at $500^{\circ} \mathrm{C}$ for $12 \mathrm{~h}$ ).

The sample unit employed was a $0.10 \mathrm{~m}^{2}$ quadrat excavated to a depth of at least $30 \mathrm{~cm}$. There were 390,728 quadrats in the study area. A computer program was used to select 10 quadrats at random from each strata for each survey. The computer calculated 
the angle and distance from a given base stake to the northeast comer of each randomly selected quadrat. We used a surveyor's transit and a $100 \mathrm{~m}$ fiberglass tape to locate each selected quadrat and a wooden frame or a sheet metal 'cookie cutter' to delineate the quadrat before excavation. About 8 person-days were required to sample the 80 units for a given survey. Fourteen surveys were conducted at approximately monthly intervals between March 1979 and May 1980, and 2 additional surveys were conducted in August and September 1980. Five rather than 10 units were sampled in each stratum in December 1979. June and July 1980 samples were collected from only 4 strata and were not used for population estimation.

All excavated sediment was washed through a $2.0 \mathrm{~mm}$ sieve. Crabs less than $5 \mathrm{~mm}$ in carapace width were not retained consistently by the sieve and were excluded from analyses of numbers and biomass. Crabs, segregated by sample unit, were transported to the laboratory where carapace width, sex and reproductive stage (females) were determined. Subsamples of crabs, selected to encompass the observed size range and dried at $90^{\circ} \mathrm{C}$ for at least $36 \mathrm{~h}$, provided data for computing dry-weight/carapace-width regressions for estimation of population biomass. Separate regressions were calculated for males, non-ovigerous females and ovigerous females because fiddler crabs are sexually dimorphic and because we wished to develop a method for estimating indirectly the sponge weight of ovigerous females. We calculated average density, biomass, total numbers, total biomass and the associated standard errors, using unbiased statistical estimators for a stratified random sampling design (Cochran, 1963). Standard errors associated with population biomass estimates do not include error associated with the regression estimate of biomass for individual crabs because that error was trivial in relation to biomass variation from quadrat to quadrat.

Growth patterns were determined by graphical analysis of the progression of modes in successive size frequency distributions. We distinguished modes in the size frequency distributions for each sex by plotting cumulative size frequencies on a probit scale (Cassie, 1954).

\section{RESULTS AND DISCUSSION}

\section{Sediment properties}

Analysis of sediment cores revealed that mean particle size $(\mathrm{mm})$ displayed a relatively uniform vertical distribution below $1 \mathrm{~cm}$. Organic matter and silt-clay were concentrated in the top $1 \mathrm{~cm}$ over the whole area. For this uppermost $\mathrm{cm}$, Strata 1 to 4 had slightly lower particle size $(0.213 \mathrm{~mm})$ and higher organic matter $(2 \%)$ and silt-clay $(12 \%)$ contents. Stratum 5, located at the only inlet abutting the site, had the coarsest sediment $(0.255 \mathrm{~mm})$ and lowest organic $(0.6 \%)$ and silt-clay ( $1 \%$ ) contents. The upper 3 strata ( 6 to 8 ) were intermediate between Strata 1 to 4 and 5 in their coarseness $(0.235 \mathrm{~mm})$, organic matter $(1 \%)$ and siltclay $(4$ to $5 \%$ ) percentages. The homogeneity of the vertical sediment profiles on the study area is probably due to bioturbation by the fiddler crabs (Allen and Curran, 1974).

\section{Population dynamics}

A total of 6,358 crabs ( $\geq 5 \mathrm{~mm}$ ) were collected from 1,240 randomly selected $0.10 \mathrm{~m}^{2}$ quadrats during the regular monthly surveys, and these provided the data base for analyses of numerical abundance, biomass and somatic growth. An additional 663 crabs ( $\geq 5 \mathrm{~mm}$ ) were collected in June and July 1980 during surveys restricted to Strata 1, 2,6 and 7. These additional crabs were included in analyses of reproduction and lateral movements across the study area.

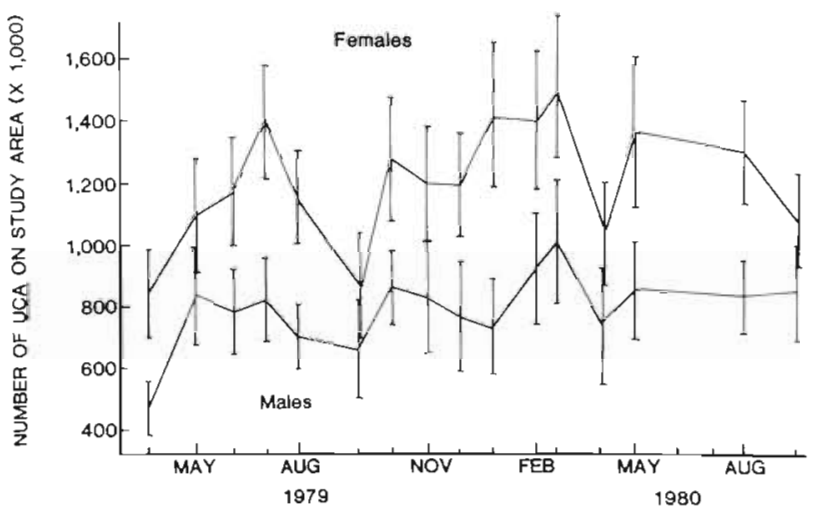

Fig. 3. Uca pugilator. Changes over time in total numbers (CW $\geq 5 \mathrm{~mm}$ ) on the 3.91 ha study area on Shackleford Banks. Vertical bars: $95 \%$ confidence limits

Numbers of fiddler crabs $(\geq 5 \mathrm{~mm})$ fluctuated between $1,348,000$ and $2,544,000$ over the $18 \mathrm{mo}$ period (Fig. 3). From May 1979 to May 1980 there was a net increase of 302,800 (31\%) females but only 9,760 (1\%) males. Measured from August 1979 to August 1980 , the increases are more equivalent for the 2 sexes: $210,000(24 \%)$ for the females and $151,400(22 \%)$ for the males. Trends in numerical abundance over time were generally parallel for the 2 sexes. One exception, May to June 1979, when males decreased and females increased, may have been due to higher predation on males by Hudsonian Curlews, Numenius phaeopus (Colby and Fonseca, in prep.). 


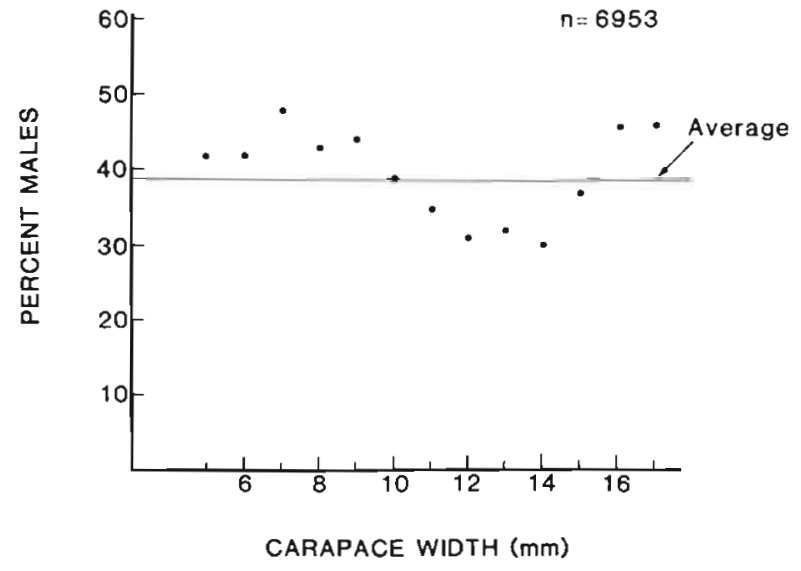

Fig. 4. Uca pugilator. Sex ratios in relation to carapace width. Crabs providing these data were excavated from 1,280 randomly selected $0.10 \mathrm{~m}^{2}$ quadrats; 68 additional crabs were excluded from analysis because their sex could not be determined with certainty

Females were consistently more abundant than males. When we examined sex ratio in relation to size following the approach of Wenner (1972), we found that females outnumbered males in every size class, but the discrepancy was greatest between 11 and $14 \mathrm{~mm}$ (Fig. 4). The larger discrepancy in this size interval may have resulted from the tendency of reproductively active females to defer somatic growth (Christy, 1980; and see below), thereby causing them to accumulate in the 11 to $14 \mathrm{~mm}$ size interval. It may also be a consequence of the fact that ovigerous females spend 12 to $14 \mathrm{~d}$ sequestered in sealed terminal chambers of their mates' burrows (Christy, 1980), and thus may be less available to predators during the reproductive season.

Montague (1980) reviewed a series of investigations of western Atlantic and Venezuelan species of $U c a$ that have consistently found males more abundant than females. However, he went on to point out that because Uca are polygynous, one would expect the sex ratios to favor females, and he suggested that the observed predominance of males might be an artifact of the sampling methods that had been employed by the various investigators. Apparently our data are the first to describe a population dominated by females. In a separate study that involved our sampling widely dispersed sites over the remainder of the 40 ha sandflat, we also found that females were consistently more abundant than males, indicating that the sex ratio we observed on our study area was consistent with that for the entire population of crabs ( $\geq 5 \mathrm{~mm}$ ) on the sandflat.

Part of the variation in numbers and biomass of larger crabs may have been caused by movements of crabs between the study site and adjacent areas of the sandflat. Such movements could have obscured or amplified seasonal changes in both parameters. During the summer of 1977, Salmon and Hyatt (1983) used traps to measure variations in lateral movements of fiddler crabs on a portion of the sandflat adjacent to our study area. Their data exhibit a marked periodicity; trap captures were especially high during the new moon phase of the lunar cycle.

We observed 2 distinct types of lateral movements by the crabs. The first involved intermittent formation of large temporary aggregations, or droves (Herrnkind, 1968), that appeared to move aimlessly over the sandflat. The function of this behavior is unknown, but it may serve to redistribute periodically the crabs in a manner that adjusts densities to food resources (Aspey, 1978). We measured 102 crabs (28 males and 74 females) collected from large nomadic droves at midday on August 8, 1979 and found all were large enough to be sexually mature (at least $10 \mathrm{~mm}$ in carapace width). This finding implies that any lateral redistribution resulting from the formation and movement of nomadic droves will only entail adults; some other mechanism is apparently responsible for lateral shifts of juveniles.

A second, more subtle, type of movement was detected only when we used time-lapse photography to examine emergence of crabs from a $4 \mathrm{~m}^{2}$ plot as the tide ebbed. These films revealed that substantial numbers of crabs moved as individuals across the $4 \mathrm{~m}^{2}$ camera field in an easterly direction. We have no data to evaluate how frequently such movements occur. Unlike the herding behavior, this kind of movement involved juvenile as well as adult crabs.

Indirect evidence of lateral movements of adult crabs within the study area is provided by the 5 -fold increases in adult crabs on Strata 1 and 2 during summer (Fig. 5). Simultaneous changes on other strata, though less clear, suggest that the changes on Strata 1

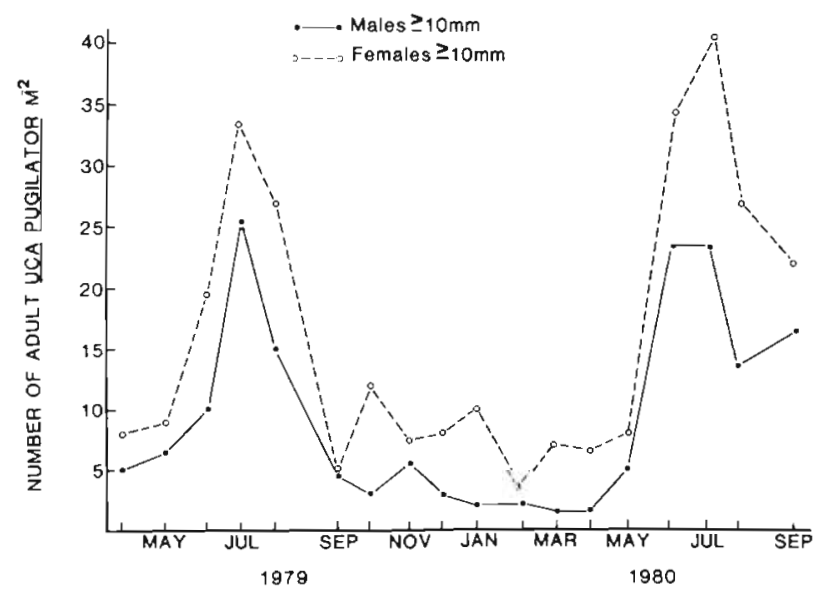

Fig. 5. Uca pugilator. Combined densities of adults $(\mathrm{CW}$ $\geq 10 \mathrm{~mm}$ ) on Strata 1 and 2 
Table 1. Correlation coefficients for numerical abundance between pairs of strata for adult ( $\geq 10$ mm) Uca pugilator males (upper triangular matrix) and females (lower triangular matrix). Eighteen pairs of observations were used in computing coefficients between Strata 1,2,6 and 7; 16 pairs of observations were used in computing the remaining coefficients

\begin{tabular}{|c|c|c|c|c|c|c|c|c|c|c|}
\hline \multicolumn{11}{|c|}{ STRATA } \\
\hline & & 1 & 2 & 3 & 4 & 5 & 6 & 7 & 8 & \\
\hline \multirow{8}{*}{ STRATA } & 1 & - & +0.38 & -0.68 & +0.87 & -0.18 & -0.58 & -0.64 & -0.63 & \multirow{8}{*}{ MALES } \\
\hline & 2 & +0.43 & - & -0.28 & +0.34 & -0.44 & -0.49 & -0.54 & -0.41 & \\
\hline & 3 & +0.12 & -0.03 & - & +0.01 & +0.37 & +0.26 & +0.29 & +0.38 & \\
\hline & 4 & +0.81 & +0.60 & +0.27 & - & -0.27 & -0.76 & -0.61 & -0.82 & \\
\hline & 5 & +0.08 & -0.22 & +0.31 & +0.16 & - & +0.43 & +0.49 & +0.03 & \\
\hline & 6 & -0.02 & +0.17 & +0.09 & -0.45 & +0.17 & - & +0.65 & +0.63 & \\
\hline & 7 & -0.39 & -0.32 & -0.15 & -0.58 & +0.05 & +0.42 & - & +0.74 & \\
\hline & 8 & -0.35 & -0.68 & +0.11 & $\begin{array}{c}-0.54 \\
\text { FEMALES }\end{array}$ & +0.36 & +0.43 & +0.47 & - & \\
\hline
\end{tabular}

and 2 probably resulted in part from lateral east-west shifts of substantial numbers of large crabs. To examine this possibility we computed correlation coefficients between pairs of strata for number of crabs $(\geq 10 \mathrm{~mm}$ ) in each of the successive surveys (Table 1). The correlations, although generally higher for males than for females, exhibited essentially the same pattern. Abundance tended to be positively correlated among Strata 1, 2 and 4 and also among Strata 5 to 8. In contrast, crab abundance on Strata 1, 2 and 4 tended to be negatively correlated with abundance on Strata 5 to 8 , as we would expect if substantial numbers of crabs were shifting back and forth between the lower strata and the upper strata. The correlations between Stratum 3 and the other strata were generally lower, but changes in abundance on Stratum 3 were more closely associated with changes in the 4 upper strata (5 to 8) than with changes in the strata immediately adjacent to it. Changes in numbers on a given stratum from survey to survey thus appear to be partly the result of adult crabs moving up or down the elevational gradient. Whether this movement is accomplished en

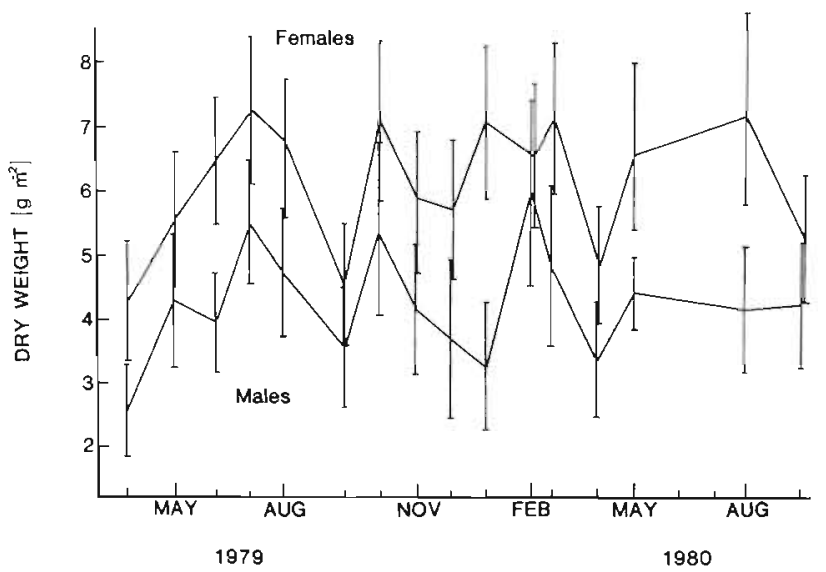

Fig. 6. Uca pugilator. Changes in average biomass over time. Vertical bars: $95 \%$ confidence limits masse in the form of nomadic droves or by the independent movement of individuals is unknown, but the fact that only adults were involved suggests the former.

The estimated total dry weight of $U_{C a}$ pugilator varied between $266.7 \mathrm{~kg}$ and $497.9 \mathrm{~kg}$ over the $18 \mathrm{mo}$ period. Overall average biomass was $4.30 \mathrm{~g} \mathrm{~m}^{-2}$ for males and $6.12 \mathrm{~g} \mathrm{~m}^{-2}$ for females. As might be expected, changes in biomass over time (Fig. 6) generally paralleled changes in numbers (Fig. 3). A notable exception occurred in March 1980 when numbers of males increased but biomass decreased.

The equations used for computing dry weight biomass from carapace width (CW) were of the form: dry weight $=\mathrm{a}(\mathrm{CW})^{\mathrm{b}}$, where $\mathrm{a}$ and $\mathrm{b}=$ fitted constants. For males $\mathrm{a}=0.006295, \mathrm{~b}=3.368615, \mathrm{n}=100$ and $\mathrm{r}^{2}=0.986$ (see also discussion of Fig. 12, below). For non-ovigerous females $\mathrm{a}=0.0000812, \mathrm{~b}=$ $3.178621, \mathrm{n}=97$ and $\mathrm{r}^{2}=0.967$. For ovigerous females $\mathrm{a}=0.00017656, \mathrm{~b}=2.937753, \mathrm{n}=45$ and $\mathrm{r}^{2}=0.914$.

An indirect estimate of the dry weight of spawn for a female of a given size can be obtained by subtracting the estimated weight of a non-ovigerous female of that size from the estimated weight of an ovigerous female of the same size. A second degree polynomial ( $\mathrm{S}=$ $-0.09179+0.01629(\mathrm{CW})-0.0004177(\mathrm{CW})^{2} ; \mathrm{r}^{2}=$ 0.996 ) accurately describes the relation and implies that spawn weight, $S$, increases with carapace width over the interval 6.9 to $19.5 \mathrm{~mm}$ and then declines. We never collected females over $19.5 \mathrm{~mm}$ in carapace width however, and ovigerous females less than $10 \mathrm{~mm}$ in carapace width are rare in this population (see below).

Wolf et al. (1975) conducted an extensive survey of a Uca pugnax population on the Duplin estuary marsh in Georgia and their data permit several comparisons between the 2 species. Whereas females consistently predominated in our samples, males always predominated in their samples of $U$. pugnax. Densities of $U$. pugilator ( $\geq 5 \mathrm{~mm}$ ) varied from 34 to $65 \mathrm{~m}^{-2}$ whereas 
the corresponding average density for $U$. pugnax was $113 \mathrm{~m}^{-2}$. Densities of crabs $\geq 5 \mathrm{~mm}$ that we observed bracketed those in other studies of $U$. pugilator (41 to $52 \mathrm{~m}^{-2}$ ) (Teal, 1958; Hockett and Kritzler, 1972). Finally, our estimates of average biomass of 4.30 and $6.12 \mathrm{~g} \mathrm{~m}^{-2}$ for males and females, respectively, contrast with corresponding male/female estimates of 6.16 and $3.63 \mathrm{~g} \mathrm{~m}^{-2}$ presented by Wolf et al. (1975). It is of interest that total biomass (both sexes) of the 2 species differs by only $6 \%$. The similarity in biomass, yet disparity in numbers implies that the average size of a crab was greater in the $U$. pugilator population.

Another population of Uca pugnax was studied by Krebs and Valiela (1978) in a marsh in Massachusetts. They reported average densities of $518 \mathrm{crabs} \mathrm{m}^{-2}$ (control plots), 401 of which had carapace widths less than $5 \mathrm{~mm}$. They reported a mean standing crop of $29 \mathrm{~g} \mathrm{dry}$ weight $\mathrm{m}^{-2}$, but a regression equation they used to estimate dry weight from carapace width gave unreasonably high estimates. In addition, they apparently used this single regression for both sexes, ignoring the sexual dimorphism of this organism.

Several methods have been employed in estimating abundance of fiddler crabs. Krebs and Valiela (1978) estimated densities of Uca pugnax by counting the numbers of burrows on sample plots. Kerwin (1971) also used this method on $U$. minax. This approach would have been subject to considerable bias for our study area because the number of open burrows varies markedly over the period the flat is exposed, with some crabs closing burrows when surface temperatures get high and most closing their burrows prior to inundation by the incoming tide. And, of course, during cooler parts of the year the crabs often fail to emerge at all. A final source of bias with the burrow counting method is the fact that gravid females remain in the burrow of their mate during the $12 \mathrm{~d}$ period between copulation and release of the zoea (Christy, 1980) and therefore there are fewer burrows than crabs.

Hockett and Kritzler (1972) applied both markrecapture (Lincoln Index) methods and stratified random sampling of $1.0 \mathrm{~m}^{2}$ quadrats in a comparative study and found that the 2 approaches provided very similar estimates, but that the mark-recapture approach was less laborious and less disruptive of the habitat. An aspect of the mark-recapture technique that made it unsatisfactory for our study is the fact that it cannot be used during the colder periods when crabs remain inactive and below ground.

Wolf et al. (1975) used a stratified random survey design to estimate abundance of Uca pugnax on a 1,058 ha marsh in Georgia. Their sample units were $1.0 \mathrm{~m}^{2}$ and they used a removal method of population estimation to avoid the necessity of excavating every sample unit. Ward and Howes (1974) also used this method, and Frey et al. (1973) found it is also applicable to 4 other species of marsh crabs. The removal method has the disadvantage that it can only be used during warmer seasons when the crabs are active at the surface (Shanholtzer, 1973), and it does not sample all segments of the population (e.g. gravid females) that remain sealed in a chamber below ground (Christy, 1980).

Hoisaeter and Matthiesen (1979) censused the fiddler crabs (a mixed aggregation of at least 6 species) on a $11.5 \mathrm{~m}^{2}$ area using $0.04 \mathrm{~m}^{2}$ sample units. They then used these data to provide a convincing demonstration of the applicability and reliability of probability survey techniques by conducting sampling surveys of this completely known sampling universe.

We found that our approach was practicable throughout the year and that it provided standard errors of estimates on the order of 8 to $10 \%$ of the corresponding estimates of means and totals. The requirement that the sediments be wet-sieved imposes a substantial additional labor cost if areas at considerable distance from the water's edge are included in the sampling frame. It would have been desirable to also have obtained quantitative estimates of the numbers of crabs smaller than $5 \mathrm{~mm}$ in carapace width. However, because the cost (time) of sieving is inversely related to the mesh diameter of the sieve, we did not feel the additional information was justified by the additional cost.

Our purpose in partitioning our sample area was to ensure more or less equal sampling intensity along the increasing elevation gradient extending from east to west. However, because there was a tendency for crab abundance and biomass to be relatively homogeneous within a stratum, we also achieved the more usual purpose of stratification, namely, increase in survey efficiency.

\section{Spatial dispersion}

Elliott (1977) evaluated a number of proposed measures of dispersion and concluded that if each sample contains the same number of sampling units, an index proposed by Morisita (Morisita, 1959, 1962) is a good measure of dispersion for comparative purposes. The index is

$$
I_{\delta}=n\left[\sum_{i=1}^{n} X_{i}^{2}-\sum_{i=1}^{n} X_{i}\right] \cdot\left[\left(\sum_{i=1}^{n} X_{i}\right)^{2}-\sum_{i=1}^{n} X_{i}\right]^{-1}
$$

where $\mathrm{n}=$ the number of sampling units; $\mathrm{X}_{\mathrm{i}}=$ number of organisms in the ith sample. The index may vary from

$$
1 \text { to }(n-1) \cdot\left(\sum_{i=1}^{n} X_{i}-1\right)^{-1}
$$


Fig. 7. Uca pugilator. Changes in spatial dispersion over time

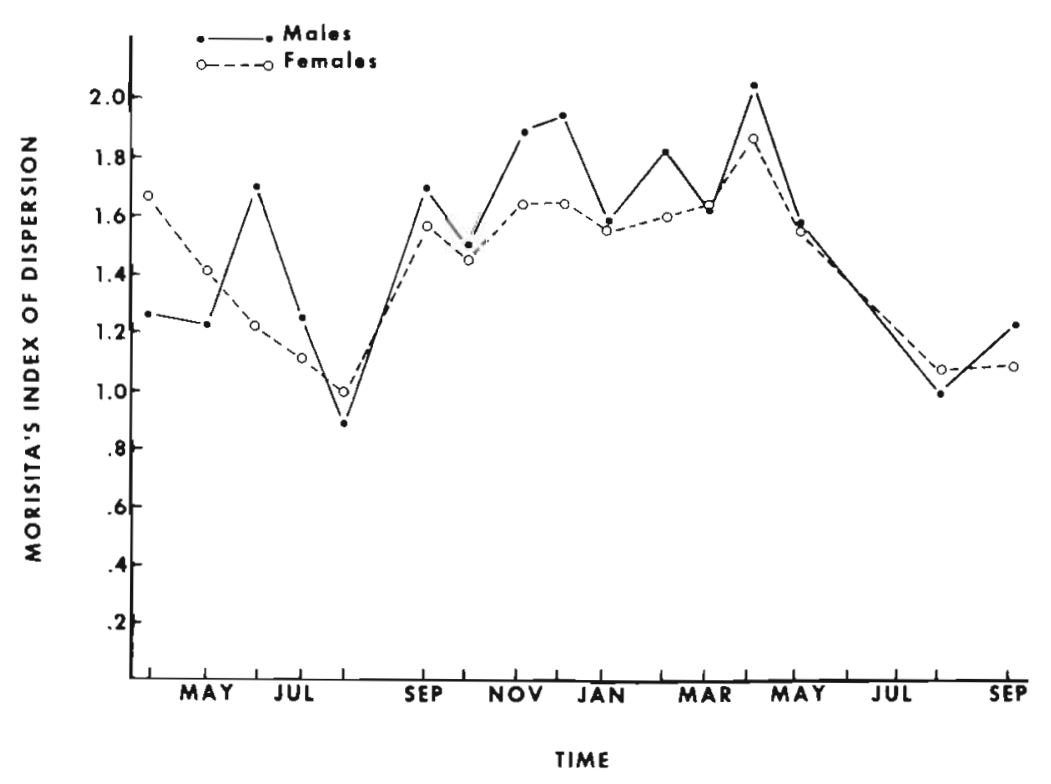

if the dispersion is one of maximum regularity, to $n$ if the dispersion is of maximum contagion. For our survey in which we sampled 80 quadrats and captured approximately 200 males and 300 females, the index could vary from about 0.60 and 0.74 respectively, to 80 . Pielou (1977) showed that if a population has a random dispersion the expected value of the index is 1.0.

Both males and females exhibited aggregated spatial dispersion over most of the 18-mo period, but in both years the dispersion, as measured by Morisita's Index, became progressively less aggregated during late spring and summer (Fig. 7). In both years by late summer the dispersion of both sexes was indistinguishable from random by the variance-mean ratio test (Elliott, 1977). Correspondence in the pattern of change in dispersion for males and females is reflected by a significant correlation between the monthly indices $(r=0.80, p<0.01)$.

The pronounced and consistent nature of the changes in dispersion during the study suggest that they are a regular seasonal feature of this population of Uca pugilator. We suspect that aggregation may decrease during the warmer months as a consequence of reproductive behavior. More frequent sampling during May-September would reveal whether the change in dispersion of one sex tends to lag behind that of the other.

Connell (1963) examined the dispersion of $U_{C a}$ pugilator in a $1 \mathrm{~m}^{2}$ plot at Woods Hole (Mass., USA) by comparing the average distance between burrows to the expected average distance if the burrows were distributed in a random pattern (Clark and Evans, 1954). He made 5 sets of measurements between May 9 and August 13 and found that the dispersion of burrows was uniform in every case except for the final
Ineasurement on August 13 when the null hypothesis of a random dispersion was not rejected. Connell points out that a uniform dispersion would be expected for a species that exhibits territorial defense behavior. As densities decreased from 84 to 34 burrows $\mathrm{m}^{-2}$, hole sizes increased, presumably in response to growth of the survivors, average distance to a nearest neighbor increased, and the pattern changed from uniform to random.

Because Connell's methodology differed from ours, direct comparison of the patterns of dispersion for the 2 populations requires some caution. His measurements were based upon burrows rather than crabs and therefore did not distinguish among males and females, and all his measurements were made on a single $1 \mathrm{~m}^{2}$ plot; in contrast, ours were, at any given time, based upon eighty $0.1 \mathrm{~m}^{2}$ plots randomly selected within a 3.91 ha area. It is therefore possible that apparent differences in dispersion were due to differences in scale or arose because of multiple occupancy of burrows during the reproductive season (Christy, 1980; Salmon and Hyatt, 1983).

Christy (1980) also used the nearest neighbor approach of Clark and Evans (1954) to measure dispersion of UCa pugilator burrows in Florida. He restricted his analysis to the dispersion of hooded burrows of sexually active males between March and September. Measurements were made on 20 plots varying in size from 0.59 to $4.66 \mathrm{~m}$. In 18 of the 20 plots the dispersion of breeding burrows was even; in the other 2 the dispersion was indistinguishable from random. The tendency for hooded breeding burrows to be uniformly spaced held over a range of densities from 4.4 to 35.0 males $\mathrm{m}^{2}$, leading Christy to infer that both interactions between residents and interactions between resi- 
dents and wanderers were involved in maintaining the uniform spacing.

Neither Morisita's index, Io nor Clark and Evan's index, $R$, is an entirely satisfactory measure of spatial dispersion because they only measure how much dispersion departs from randomness. Pielou (1977) distinguished between 2 aspects of spatial pattern, intensity and grain. Intensity refers to the degree to which density varies from one location to another. Grain, on the other hand, refers to the relative size of clumps and how widely spaced they are. She pointed out that both Morisita's index and Clark and Evan's index measure only the intensity of a pattern. Because indices of dispersion are based upon either distance measurements or frequencies of capture per sample unit, they fail to incorporate information on the spatial location of the organisms or sample units and hence are an inadequate substitute for maps showing numbers of animals by location.

\section{Reproduction}

Ovigerous females were encountered only from May through August, implying that reproduction begins in the latter half of April and ends before mid-September. These observations are supported by data from Dudley and Judy (1971) who sampled inshore waters adjacent to Beaufort Inlet for crab larvae from May through November, but collected no zoea of $U c a$ spp. later than September. The pattern of frequency of ovigerous

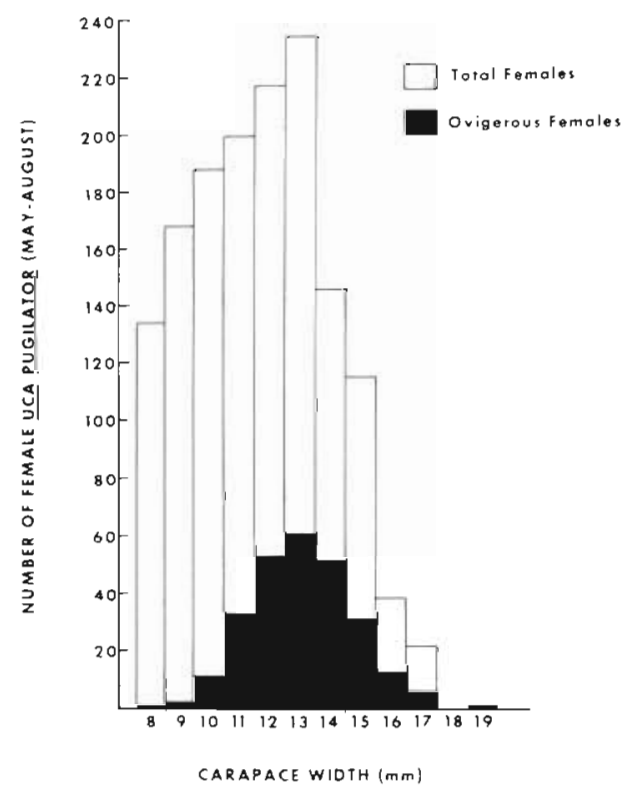

Fig. 8. Uca pugilator. Size distributions of 273 ovigerous fernales and of all 1.463 females $\geq 8.0 \mathrm{~mm}$ collected in the monthly surveys conducted during the reproductive seasons of 1979 and 1980 females across the reproductive season did not differ between the 2 yr of our study (chi-square $=6.12,3 \mathrm{df}$ ). The size distribution of ovigerous females was remarkably symmetrical in contrast to the corresponding distribution for all females $\geq 8 \mathrm{~mm}$ carapace width collected from May through August (Fig. 8). Only $1 \%$ of ovigerous females were $\leq 10 \mathrm{~mm}$ in carapace width, and less than $1 \%$ were $\geq 18 \mathrm{~mm}$. The average carapace width of ovigerous females was $13.6 \mathrm{~mm}$. There was no tendency for the percentage of ovigerous females to increase with size for crabs $>13 \mathrm{~mm}$. Hyatt (1977) has shown that males of this species from a population $3.4 \mathrm{~km}$ away also become sexually mature when they attain a carapace width of 8-13 mm.

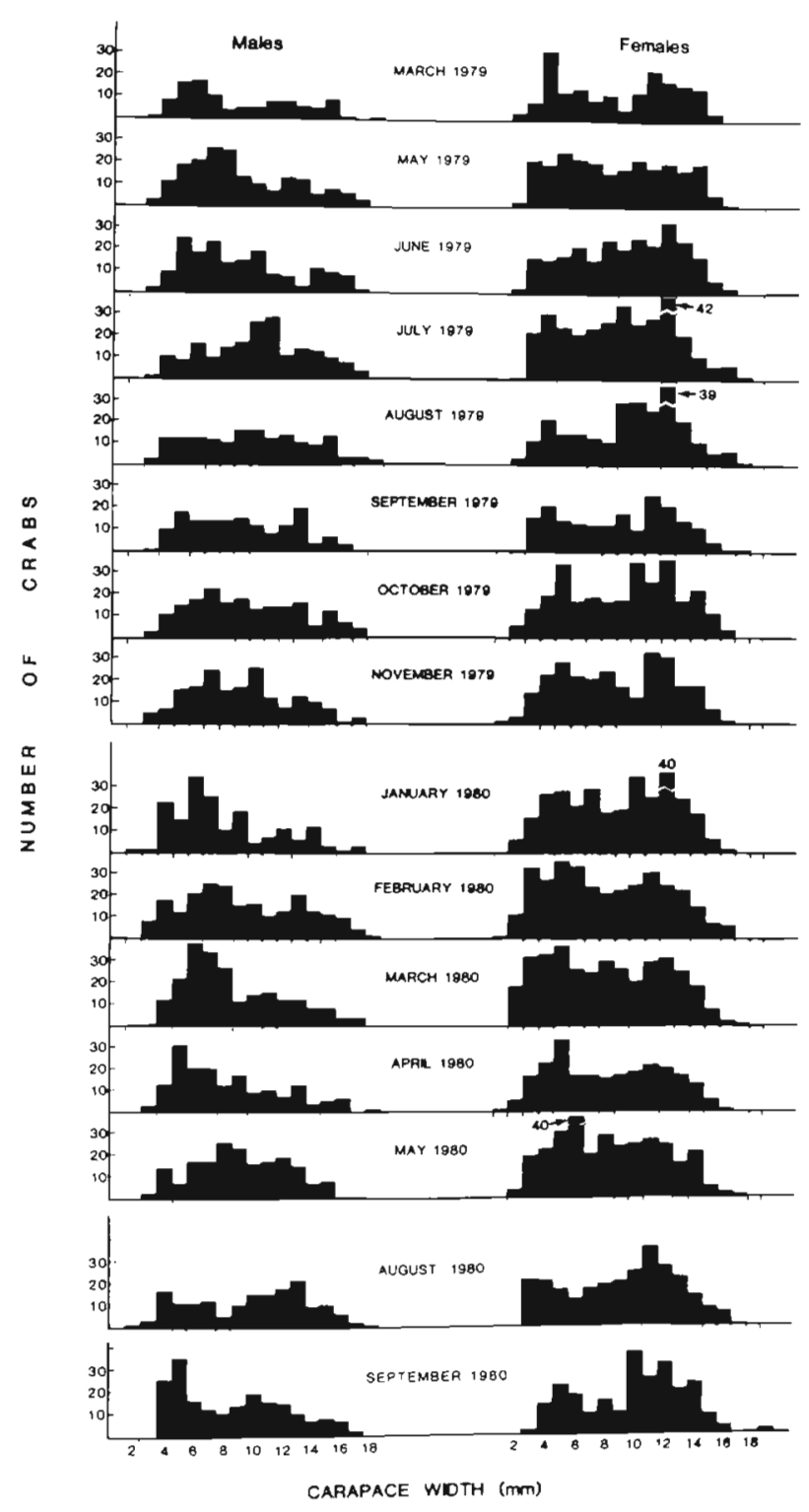

Fig. 9. Uca pugilator. Size frequency distributions of individuals collected between March 1979 and September 1980 
Fig. 10. Uca pugilator, Estimated growth in carapace width of individuals hatched in 1977, 1978 and 1979, and collected in surveys in 1979 and 1980 based upon progression of size-class modes through time

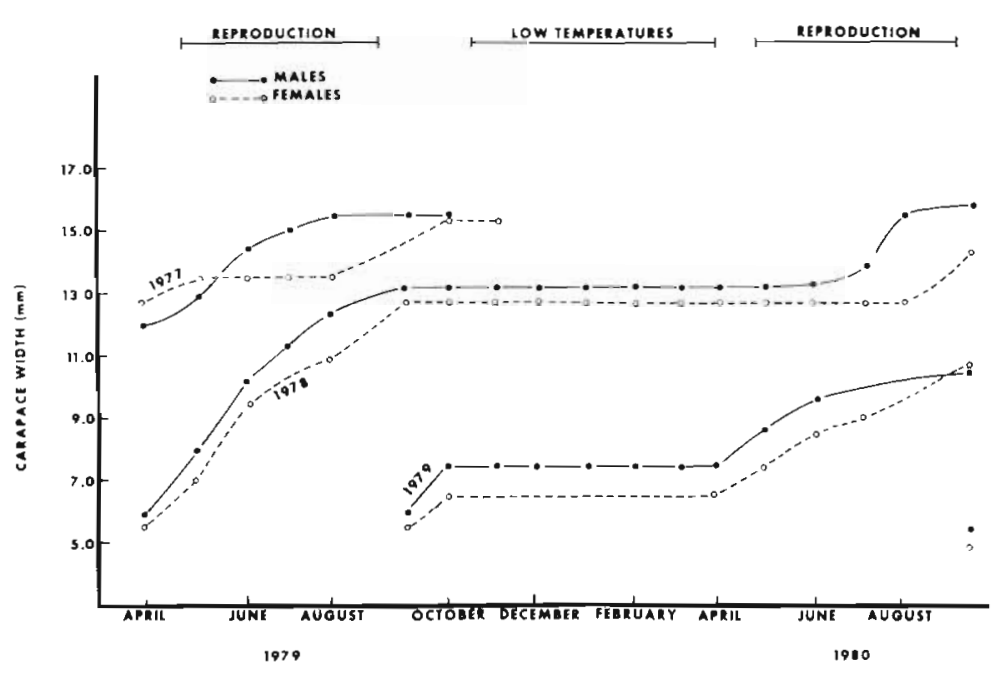

growth of males appears to be more continuous during the warmer months, even though Hyatt (1977) has found that their feeding rates drop sharply during periods of courtship. Sexually mature females apparently are able to catch up in size to males in their cohort during the early fall, following the reproductive season and prior to the onset of lower temperatures that limit feeding. Both males and females of the 1979 cohort did not grow as much in their second season of growth (summer of 1980) as members of the 1978 cohort did in their second season of growth during the preceding summer (Fig. 10). This diminished somatic growth rate coincided with an approximately $23 \%$ increase in the numerical abundance of crabs on the study area from August 1979 to August 1980, suggesting resource limitation related to increased population size may have been responsible.

Growth in carapace width over the life span of a hypothetical crab (based upon average rates derived
Fig. 11. Uca pugilator. Growth in carapace width of male (solid line) and female (dashed line) hatched in May and June

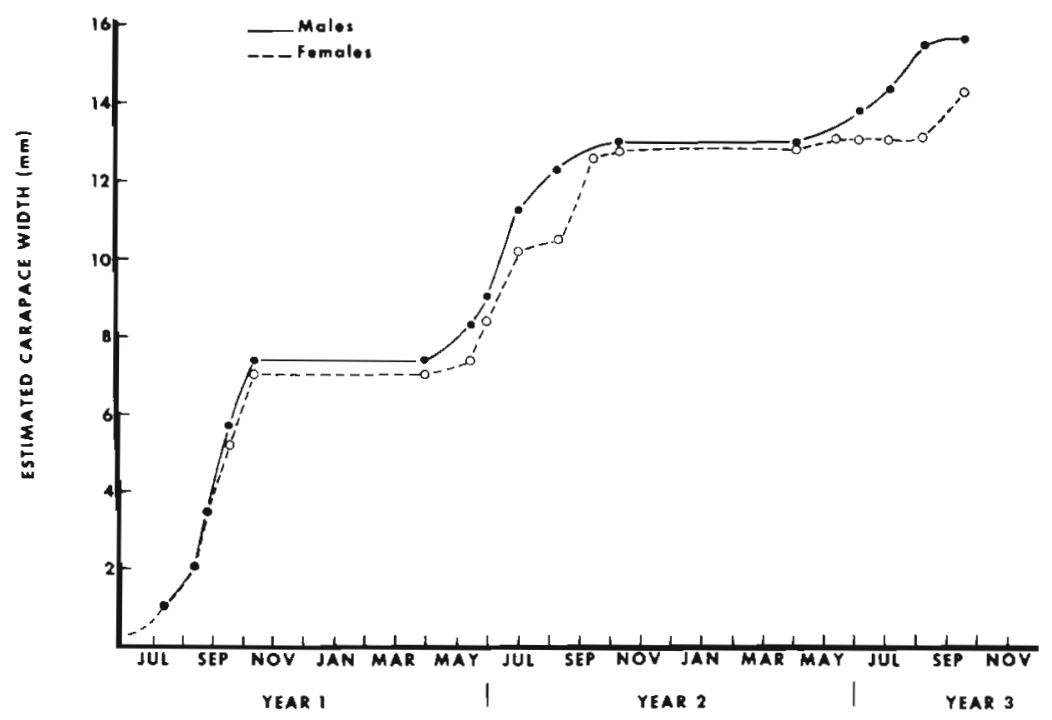




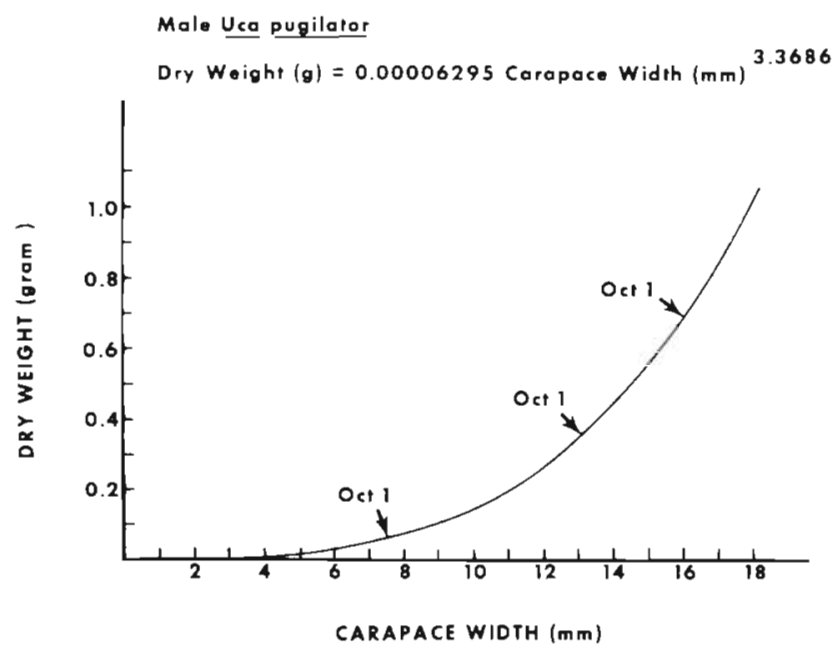

Fig. 12. Uca pugilator. Relation between dry weight and carapace width for a male; arrows: dry weight it would attain during successive Octobers of its life

from Fig. 10) that hatches in May or June is shown in Fig. 11. Dry weight increases exponentially with a linear change in carapace width (Fig. 12). Thus, a male that weighs about $50 \mathrm{mg}$ on October 1 of its first year will have increased its weight by $700 \%$ one year later, and if it survives to see a third October, it will double its weight again. The relation between dry weight and carapace width for Uca pugilator is similar to that reported for $U$. pugnax by Shanholtzer (1973).

Hopkins (1982) reported somatic growth rates for Uca pugilator reared in a laboratory on a diet of oatmeal. Her crabs grew very slowly and if we use her average intermolt cycle of $70 \mathrm{~d}$ and her average percentage increase in carapace width per molt of $2.4 \%$, it would take more than 9 yr for a male to grow to $16.4 \mathrm{~mm}$. Therefore we do not believe that the growth rates she reported accurately characterize those of free-living $U$. pugilator in a natural population.

\section{Concluding remarks}

A stratified random survey design proved to be practical and easy to implement in this study. Locating specific sample units in the field, selected from among many thousands, was done quickly and with a minimum of difficulty. The design permitted subdivision of the study area into ecologically relevant zones (strata) and, like other probability sampling designs, offered the substantial advantage of providing for unbiased estimation of parameters (Cochran, 1963). Because of the necessity of wet-sieving sediments to recover crabs, it was not feasible to include the entire sandflat in our study area and this led to later problems of data interpretation because immigration and emigration were not measured. The advantages of dealing with a 'closed' population in an investigation of this type are obvious.

The consistent predominance of females in our samples was unusual because previous investigations of fiddler crab populations have invariably reported an excess of males (see review by Montague, 1980). We believe, however, that our sampling methodology did not differentially sample the 2 sexes. The greater abundance of females was also apparent in time-lapse films of crabs engaged in surface activities, and in samples excavated from elsewhere on the sandflat beyond the boundaries of the study area.

Because biomass increases exponentially with respect to carapace width, size frequency distributions do not indicate the degree to which the older members of the population contribute to total biomass. For example, only $9 \%$ of the males were $15 \mathrm{~mm}$ or greater in carapace width, but they constituted $33 \%$ of the male biomass. Wolf et al. (1975) estimated abundance of Uca pugnax by collecting crabs from the surface of $1 \mathrm{~m}^{2}$ quadrats that had been enclosed during the previous high tide. To the extent that different sampling methodology does not invalidate comparison of our data for $U$. pugilator with theirs for $U$. pugnax, several interesting contrasts emerge. Despite the fact that sex ratios and male-female biomass ratios were the reverse of one another and that numerical abundance was substantially higher in the $U$. pugnax population, total biomass per unit area was very similar. This similarity in total biomass per unit area is striking given the complexity of the marsh habitat in comparison to the relatively homogenous nature of the sandflat habitat of this study.

Our estimates of growth patterns were based primarily on subjective evaluation of the progression of modes of the size frequency distributions. Shanholtzer (1973) on the other hand utilized a technique proposed by Cassie (1954) to distinguish cohorts in size frequency distributions of Uca pugnax. We applied Cassie's (1954) approach to our data and found that it too requires subjective decisions as to the number and location of points of inflection on the cumulative size distribution plot. These analyses confirmed our original evaluations where modes were obvious but similarly led to tenuous decisions where they were not. Larger samples sizes would perhaps have clarified modes of some of the size frequency distributions, but we doubt that the growth patterns would differ substantially from those we have presented.

Finally, the progressive change in dispersion from spring to early fall deserves further study, both to test its generality and to discover the underlying mechanism responsible for this process. 
Acknowledgements. Sampling a fiddler crab population by excavating and wet-sieving sediments from $1,320,0.1 \mathrm{~m}^{2}$ sample units is laborious. More than 30 of our colleagues assisted in the field work over the course of the project, some even as cheerful, unpaid volunteers. Still others have assisted in data processing or provided stimulating discussion or constructive criticism of this manuscript. Mr. Herbert Gordy prepared the figures. To all these people we extend our thanks. This research was supported partially by an Interagency Agreement between the Department of Energy and the National Marine Fisheries Service, NOAA.

\section{LITERATURE CITED}

Allen, E. A., Curran, H. A. (1974). Biogenic sedimentary structures produced by crabs in lagoon margin and salt marsh environments near Beaufort, North Carolina. J. sedim. Petrol. 44: 538-548

American Society for Testing and Materials (A.S.T.M.) (1963). Standard method of particle size analysis of soils. A.S.T.M. designation D422-63, p. 205-217

Aspey, W. P. (1978). Fiddler crab behavioral ecology: burrow density in Uca pugnax (Smith) and Uca pigulator (Bosc) (Decapoda Brachyura). Crustaceana 34: 235-244

Cassie, R. M. (1954). Some uses of probability paper in the analysis of frequency distributions. Aust. J. mar. Freshwat. Res. 5: 513-522

Christy, J. H. (1980). The mating system of the sand fiddler crab, Uca pugilator. Ph. D. Dissertation, Cornell University, Ithaca, N. Y.

Clark, P. J., Evans, F. C. (1954). Distance to nearest neighbor as a measure of spatial relationships in populations. Ecology 35: $445-453$

Cochran, W. G. (1963). Sampling techniques. Wiley, New York

Connell, J. H. (1963). Territorial behavior and dispersion in some marine invertebrates. Researches Popul. Ecol. Kyoto Univ. 5: 87-101

Crane, J. (1975). Fiddler crabs of the world, Ocypodidae: genus Uca. Princeton University Press, Princeton, N. J.

Dudley, D. L., Judy, M. H. (1971). Occurrence of larval, juvenile, and mature crabs in the vicinity of Beaufort Inlet, North Carolina. NOAA Tech. Rep. NMFS SSRF-637

Elliott, J. M. (1977). Some methods for the statistical analysis of samples of benthic invertebrates. Freshwater Biological Association, Ambleside

Folk, R. L., Ward, W. C. (1957). Brazos River Bar: a study in the significance of grain size parameters. J. sedim. Petrol. 27 . 3-26

Frey, R. W., Basan, P. B., Scott, R. M. (1973). Techniques for sampling salt rnarsh benthos and burrows. Am. Midl. Nat. 89: $228-234$

Hernkind, W. F. (1968). Adaptive visually-directed orientation in UCa pugilator. Am. Zool. 8: 585-598

Hockett, J. C., Kritzler, H. (1972). Capture-recapture methods with Uca. Biol. Bull. mar, biol. Lab., Woods Hole 142; $49-56$

Hoisaeter, T., Matthiesen, A. (1979). Report on some statistical aspects of marine biological sampling. San Carlos Publications, Univ, of San Carlos, Cebu City, Philippines

Hopkins, P. M. (1982). Growth and regeneration patterns in the fiddler crab, Uca pugilator. Biol. Bull mar. biol. Lab., Woods Hole 163: 301-319

Hyatt, G. W. (1977). Field studies of size-dependent changes in waving display and other behavior in the fiddler crab, Uca pugilator (Brachyura, Ocypodidae). Mar. behav. Physiol. 4: 283-292

Kerwin, J. A. (1971). Distribution of the fiddler crab (Uca minax) in relation to marsh plants within a Virginia estuary. Chesapeake Sci. 180-183

Krebs, C. T., Valiela, I. (1978). Effect of experimentally applied chlorinated hydrocarbons on the biomass of the fiddler crab, Uca pugnax (Smith). Estuar. coast. mar. Sci. 6: 375-386

Montague, C. L. (1980). A natural history of temperate western Atlantic fiddler crabs (Genus Uca) with reference to their impact on the salt marsh. Contr. mar. Sci. 23: 25-55

Morisita, M. (1959). Measuring the dispersion of individuals and analysis of the distributional patterns. Mem. Fac. Sci. Kyushu Univ. (Ser. E Biol.) 2: 215-235

Morisita, M. (1962). I-index, a measure of dispersion of individuals. Res. Popul. Ecol. Kyoto Univ. 4: 1-7

Pielou, E. C. (1977). Mathematical ecology. Wiley-Interscience, New York

Salmon, M., Hyatt, G. W. (1983). Spatial and temporal aspects of reproduction in North Carolina populations of fiddler crabs (Uca pugilator Bosc.). J. exp. mar. Biol. Ecol. 70 : $21-43$

Shanholtzer, S. F. (1973). Energy flow, food habits and population dynamics of Uca pugnax in a salt marsh system. Ph. D. Dissertation, University of Georgia, Athens

Teal, J. M. (1958). Distribution of fiddler crabs in Georgia salt marshes. Ecology 39: 185-193

Ward, D. V., Howes, B. L. (1974). The eftects of abate, an organophosphorous insecticide, on marsh fiddler crab populations. Bull. environ. Contam. Toxicol. 12: 694-697

Wenner, A. M. (1972). Sex ratio as a function of size in marine crustacea. Am. Nat. 106: 321-350

Wolf, P. L., Shanholtzer, S. F., Reimold, R. J. (1975). Population estimates for Uca pugnax (Smith 1870) on the Duplin Estuary Marsh, Georgia, USA (Decapoda, Brachyura, Ocypodidae). Crustaceana 29: 79-91 